\title{
Materials Selection, Synthesis, and Dielectrical Properties of PVC Nanocomposites
}

\author{
Youssef Mobarak, ${ }^{1,2}$ M. Bassyouni, ${ }^{3,4}$ and M. Almutawa ${ }^{5}$ \\ ${ }^{1}$ Electrical Engineering Department, King Abdulaziz University, Rabigh 21911, Saudi Arabia \\ ${ }^{2}$ Electrical Engineering Department, Faculty of Energy Engineering, Aswan University, Sahari City 81528, Egypt \\ ${ }^{3}$ Chemical and Materials Engineering Department, King Abdulaziz University, Rabigh 21911, Saudi Arabia \\ ${ }^{4}$ Chemical Engineering Department, Higher Technological Institute, Tenth of Ramadan City 11111, Egypt \\ ${ }^{5}$ Faculty of Science, King Abdulaziz University, Jeddah 21589, Saudi Arabia
}

Correspondence should be addressed to M. Bassyouni; migb2000@hotmail.com

Received 12 March 2013; Revised 20 May 2013; Accepted 21 May 2013

Academic Editor: Mohd Sapuan Salit

Copyright (C) 2013 Youssef Mobarak et al. This is an open access article distributed under the Creative Commons Attribution License, which permits unrestricted use, distribution, and reproduction in any medium, provided the original work is properly cited.

\begin{abstract}
Materials selection process for electrical insulation application was carried out using Cambridge Engineering Selector (CES) program. Melt mixing technique was applied to prepare polyvinyl-chloride- (PVC-) nanofumed silica and nanomontmorillonite clay composites. Surface analysis and particles dispersibility were examined using scanning electron microscope. Dielectrical properties were assessed using Hipot tester. An experimental work for dielectric loss of the nanocomposite materials has been investigated in a frequency range of $10 \mathrm{~Hz}-50 \mathrm{kHz}$. The initial results using CES program showed that microparticles of silica and clay can improve electrical insulation properties and modulus of elasticity of PVC. Nano-montmorillonite clay composites were synthesized and characterized. Experimental analyses displayed that trapping properties of matrix are highly modified by the presence of nanofillers. The nanofumed silica and nanoclay particles were dispersed homogenously in PVC up to $10 \% \mathrm{wt} / \mathrm{wt}$. Dielectric loss tangent constant of PVC-nanoclay composites was decreased successfully from 0.57 to 0.5 at $100 \mathrm{~Hz}$ using fillers loading from $1 \%$ to $10 \% \mathrm{wt} / \mathrm{wt}$, respectively. Nano-fumed silica showed a significant influence on the electrical resistivity of PVC by enhancing it up to $1 \times 10^{11} \mathrm{Ohm} \cdot \mathrm{m}$.
\end{abstract}

\section{Introduction}

Nanocomposites represent a very attractive route to upgrade and diversify properties of the polymers. Nanofiller-filled polymers might be differentiated from microfiller-filled polymers in three major aspects that the nanocomposites normally contain smaller amounts, are in range of nanometers in size, and have tremendously large specific surface area. All these characteristics are reflected in their material properties [1-3]. Fillers are added to polymeric materials in order to enhance physical and mechanical properties [4-7]. Over the past few years, there have been few numbers of researches on the effect of fillers on di-electric properties of polymers [8-10]. The shift from ceramic electrical insulating materials (e.g., porcelain and glass) and from oil-paper insulations to polymeric materials has been the major change in the field of high voltage insulation technology [11-13]. Today polymers are widely used in most of the high voltage equipment, for example, power transformers, insulators, capacitors, reactors, surge arresters, current and voltage sensors, bushings, power cables, and terminations. The huge scenarios of new polymer composites in high voltage technology inspire the researchers of the field to innovate new materials and to study their properties [14-16]. There is a need for developing a range of compact devices and accessories, for both outdoor and indoor conditions, in which novel and more reliable insulation systems will play the key role [17-19]. Nanomaterials, in form of polymeric nanocomposites, are foreseen as excellent candidates which are able to fulfill the new requirements [20-22]. Elemental properties are usually integrated over macroscopic volumes to reach explanations for macroscopic properties [23-26]. The new developments in nanoscience 
TABLE 1: Physical and mechanical properties of polyvinyl chloride.

Physical and mechanical properties of polyvinyl chloride (Sabic, Saudi Arabia)

\begin{tabular}{lc}
\hline Young's modulus & $3.2 \mathrm{MPa}$ \\
Shear modulus & $1.2 \mathrm{MPa}$ \\
Bulk modulus & $1.8 \mathrm{GPa}$ \\
Poisson's ratio & 0.49 \\
Yield strength (elastic limit) & $10 \mathrm{MPa}$ \\
Tensile strength & $10 \mathrm{MPa}$ \\
Compressive strength & $20 \mathrm{MPa}$ \\
Flexural strength (modulus of rupture) & $11 \mathrm{MPa}$ \\
Hardness-Shore D & 12 \\
Heat deflection temperature at $455 \mathrm{KPa}$ & $-30^{\circ} \mathrm{C}$ \\
\hline
\end{tabular}

and technology stop short of the final integration and consider what special properties are present at the nanometric level and how they might be exploited [26, 27].

PVC is widely used in industrial applications. Chemically, PVC has a structure which is similar to that of PE but instead of several hydrogen atoms, it has chlorine atoms, which are attached to the molecular chains at the side in a random manner [28-30]. Also, it has excellent forming properties, is suitable for extreme thermoforming requirements, chemically resistant, UV-stabilized, weather resistant, and has increased impact resistance [31-33]. PVC is stronger and more rigid than other general purpose thermoplastic materials. It has a high tensile strength and modulus of elasticity. Additives are used to further specific end use, such as thermal stabilizers, lubricity, impact modifiers, and pigmentation. PVC is basically tough and strong, resists water and abrasion, and is an excellent electrical insulator [34-36].

\section{Experimental}

2.1. Materials Selection for Electrical Insulation and Mechanical Properties Using CES Program. Effect of silica and clay particles on the performance of PVC can be governed by the mechanical and electrical properties. CES program (Granta Design Company) was initially used to predict the desired properties of PVC composites using different fillers (microscale)/matrix mixing ratio. Synthesis and manufacturing of PVC composites were carried out based on the obtained results using CES program.

\subsection{Raw Materials and Equipment. Polyvinylchloride (PVC)} was received from petrochemical company (Sabic, Saudi Arabia). Physical and mechanical properties of PVC are listed in Table 1. Treated nano-montmorillonite clay was purchased from Sigma Aldrich. It is montmorillonite clay (Nanomer $1.30 \mathrm{E})$, clay surface modified with 25-30 wt\% octadecylamine. Spherical particle shape is the most important characteristic of nanoclay for polymer applications. The platy nature of clay fillers has a greater effect on properties such as viscosity, stiffness, and strength. Using clay as nanofiller gives high levels of flame retardancy to produced composite. Nanofumed silica powder was obtained from Sigma Aldrich.

Hipot Tester (HIOKI 3522-50 LCR Hi-tester) device is used to measure electrical parameters of nanocomposites at various frequencies: $|\mathrm{Z}|,|\mathrm{Y}|, \theta$, Rp (DCR), Rs (ESR, DCR),G, $\mathrm{X}, \mathrm{B}, \mathrm{Cp}, \mathrm{Cs}, \mathrm{Lp}, \mathrm{Ls}, \mathrm{D}(\tan \delta)$, and Q. Specification of LCR is power supply: $100,120,220$, or $240 \mathrm{~V}( \pm 10 \%)$ AC (selectable), $50 / 60 \mathrm{~Hz}$, frequency: $\mathrm{DC}, 1 \mathrm{mHz}$ to $100 \mathrm{kHz}$, and display. Voltage rating is $220 \mathrm{VAC} 50 \mathrm{~Hz}$, test voltage is $0 \sim 5 \mathrm{KV}$ (adjustable), and output capacity is up to $1 \mathrm{KVA}$, cutoff current. PVC was mixed and pressed with nanofillers using two roll mills made of cast iron rolls, barrel dimensions $6^{\prime \prime} \times 16^{\prime \prime}$, working length $14^{\prime \prime}$, and motor capacity $7.5 \mathrm{HP}$. The samples were dried using vacuum-drying oven, at $100^{\circ} \mathrm{C}$ for 12 hours. Samples morphology was analyzed using scanning electron microscope (JEOL model JXA 840A (ADS+OM-Japan)). Monolayer of gold atoms was induced using gold sputter coater (S150 from Edwards for 6 min vacuum at $40 \mathrm{~mA}$ ).

2.3. Synthesis of Polyvinylchloride Composites. Two sets of PVC composites were prepared. In the first set, PVC was composited with nano-fumed silica (1-10\% wt/wt). Fumed silica was mixed and heated up to $200^{\circ} \mathrm{C}$ for $8 \mathrm{~min}$ using corotating twin-screw extruder (Berstorff ZE25A, Hannover, Germany) at $300 \mathrm{rpm}$. The compounded materials were ground and rolled at $185^{\circ} \mathrm{C}$ to obtain thin film (thickness of $1 \pm 0.01 \mathrm{~mm}$ ). PVC-fumed silica composites were obtained under $25 \mathrm{MPa}$ and $185^{\circ} \mathrm{C}$ for $5 \mathrm{~min}$ using hot press. In the second set, polyvinylchloride nanomontmorillonite clay was obtained using typical techniques and operating conditions.

2.4. Characterization of PVC Composites. Electrical and surface analysis of PVC-nanostructured material specimen were carried out. This was achieved by measuring dielectric properties losses, electrical resistivity, and SEM analysis. These tests are able to identify the best combination of polymersnanofillers in addition to the optimum fillers loading, in terms of improved dielectric strength and smaller space charge accumulation.

2.4.1. Electrical Properties. Dielectric spectroscopy is a powerful experimental method to investigate the dynamical behavior of a sample through the analysis of its frequencydependent dielectric response. This technique is based on the measurement of the dielectric loss constants as a function of frequency of a sample sandwiched between two electrodes. The $\tan \delta$ and susceptance (B) were measured as a function of frequency in the range from $10 \mathrm{~Hz}$ to $50 \mathrm{kHz}$ at $25^{\circ} \mathrm{C}$ for all test specimens. The measurements were made using high resolution dielectric spectroscopy.

2.4.2. SEM Analysis. The morphology and dimensions of the PVC composites were tested using scanning electron microscopy. Specimens were cut in liquid nitrogen and then coated with nanogold layers using a sputter coater to make them conductive. 


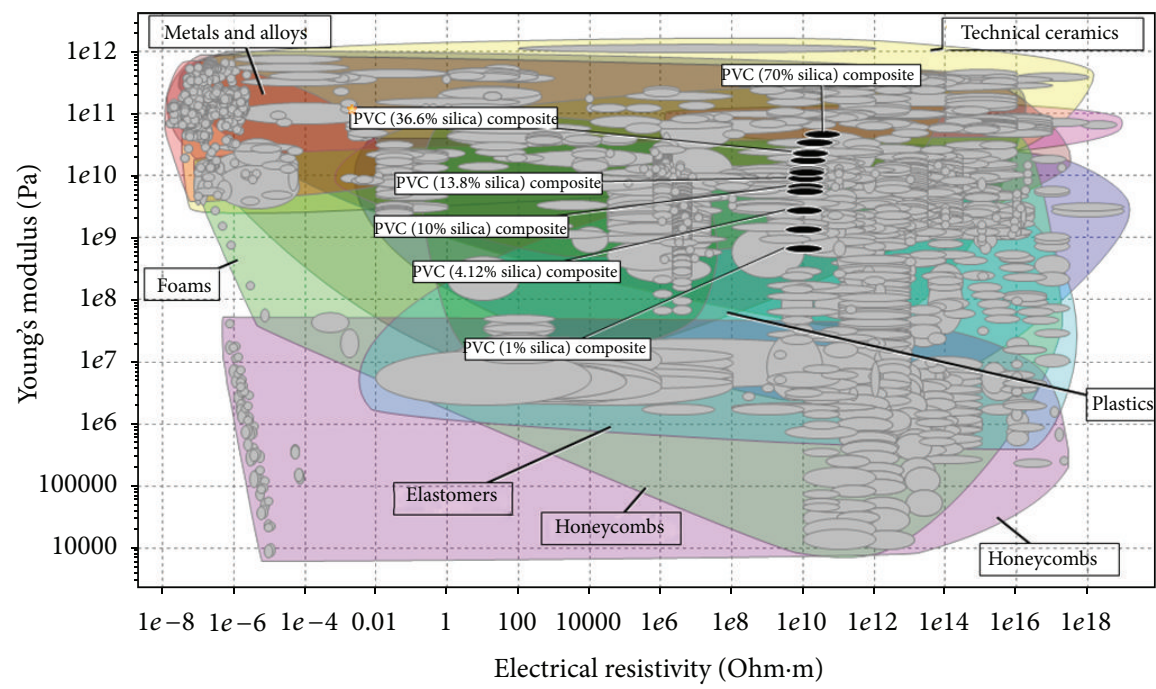

\begin{tabular}{|l|l|}
\hline $\begin{array}{c}\text { PVC-silica } \\
\text { composites }\end{array}$ & $\begin{array}{c}\text { Electrical } \\
\text { resistivity } \\
\text { (Ohm·m) }\end{array}$ \\
\hline PVC $(1 \%$ silica $)$ & $3.19 \times 10^{9}-3.19 \times 10^{10}$ \\
\hline PVC $(2.03 \%$ silica $)$ & $3.23 \times 10^{9}-3.23 \times 10^{10}$ \\
\hline PVC $(4.12 \%$ silica $)$ & $3.3 \times 10^{9}-3.3 \times 10^{10}$ \\
\hline PVC $(8.37 \%$ silica $)$ & $3.45 \times 10^{9}-3.45 \times 10^{10}$ \\
\hline PVC $(10 \%$ silica $)$ & $3.51 \times 10^{9}-3.51 \times 10^{10}$ \\
\hline PVC $(13.8 \%$ silica $)$ & $3.67 \times 10^{9}-3.67 \times 10^{10}$ \\
\hline PVC $(17 \%$ silica $)$ & $3.81 \times 10^{9}-3.81 \times 10^{10}$ \\
\hline PVC $(19.1 \%$ silica $)$ & $3.91 \times 10^{9}-3.91 \times 10^{10}$ \\
\hline PVC $(26.5 \%$ silica $)$ & $4.3 \times 10^{9}-4.3 \times 10^{10}$ \\
\hline PVC $(34.5 \%$ silica $)$ & $4.82 \times 10^{9}-4.82 \times 10^{10}$ \\
\hline PVC $(36.6 \%$ silica $)$ & $4.98 \times 10^{9}-4.98 \times 10^{10}$ \\
\hline PVC $(50.6 \%$ silica $)$ & $6.4 \times 10^{9}-6.4 \times 10^{10}$ \\
\hline PVC $(70 \%$ silica $)$ & $1.05 \times 10^{10}-1.05 \times 10^{11}$ \\
\hline
\end{tabular}

FIGURE 1: Electrical resistivity and mechanical properties of PVC-silica using CES program.

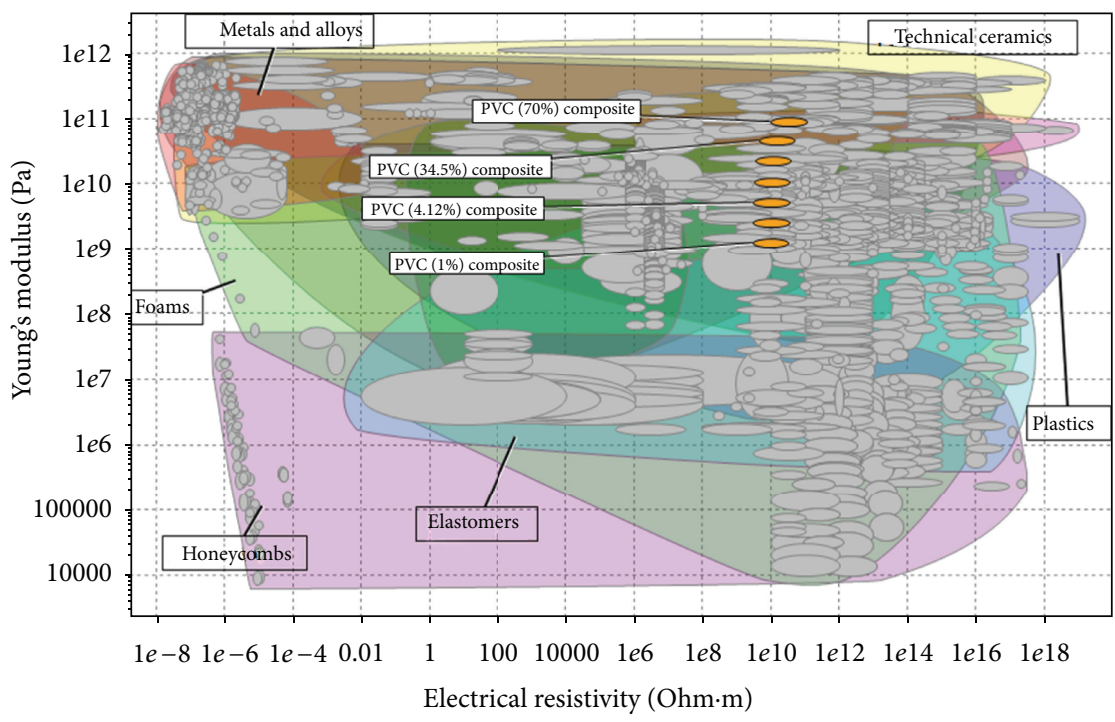

\begin{tabular}{|l|l|}
\hline \multicolumn{1}{|c|}{$\begin{array}{c}\text { PVC-clay } \\
\text { composites }\end{array}$} & \multicolumn{1}{c|}{$\begin{array}{c}\text { Electrical } \\
\text { resistivity }(\mathrm{Ohm} \cdot \mathrm{m})\end{array}$} \\
\hline PVC $(1 \%$ clay $)$ & $1.01 \times 10^{9}-1.21 \times 10^{9}$ \\
\hline PVC $(2.03 \%$ clay $)$ & $2.5 \times 10^{9}-2.72 \times 10^{9}$ \\
\hline PVC $(4.12 \%$ clay $)$ & $5.04 \times 10^{9}-5.24 \times 10^{9}$ \\
\hline PVC $(8.37 \%$ clay $)$ & $1.09 \times 10^{10}-1.15 \times 10^{10}$ \\
\hline PVC $(17 \%$ clay $)$ & $2.25 \times 10^{10}-2.27 \times 10^{10}$ \\
\hline PVC $(34.5 \%$ clay $)$ & $4.3 \times 10^{10}-4.6 \times 10^{10}$ \\
\hline PVC $(70 \%$ clay $)$ & $8.8 \times 10^{10}-9.3 \times 10^{10}$ \\
\hline
\end{tabular}

FIGURE 2: Electrical resistivity and mechanical properties of PVC-clay using CES program.

\section{Results and Discussion}

3.1. Predictable Mechanical and Electrical Behavior of PVCSilica Composites. Figure 1 illustrates the electrical and mechanical properties of PVC-silica composites using CES software. Addition of silica to PVC leads to improving the electrical resistivity of PVC. It is detected that the electrical resistivity can be increased up to $5.0 \times 10^{10} \mathrm{Ohm} \cdot \mathrm{m}$ (mean value) using $70 \%$ silica wt/wt. This can be attributed to the high electrical resistivity of silica $\left(1.0 \times 10^{12}-1.0 \times\right.$ $\left.10^{13} \mathrm{Ohm} \cdot \mathrm{m}\right)$ comparing with lower electrical resistivity value of PVC matrix $\left(3.16 \times 10^{9}-3.16 \times 10^{9} \mathrm{Ohm} \cdot \mathrm{m}\right)$. Modulus of elasticity of PVC was increased from $3 \mathrm{GPa}$ to $72 \mathrm{GPa}$ in the presence of $70 \% \mathrm{wt} / \mathrm{wt}$ silica.
3.2. Predictable Electrical and Mechanical Behavior of PVCClay Composites. Figure 2 illustrates the electrical and mechanical properties of PVC-clay composites using CES software. The initial results using the predictable model (CES software) showed that addition of clay particles to PVC can cause an increase in the electrical resistivity and modulus of elasticity. The clay fillers loading is between 1 and $70 \%$ wt/wt. Electrical resistivity was increased from $1.1 \times 10^{9}$ to $9 \times 10^{10} \mathrm{Ohm} \cdot \mathrm{m}$ (mean value). Modulus of elasticity was improved significantly from $3.190 \mathrm{GPa}$ to $93.30 \mathrm{GPa}$ with respect to clay fillers loading 1 to $70 \% \mathrm{wt} / \mathrm{wt}$.

3.3. Effect of Nanofumed Silica on Electrical Insulation of PVC. Figure 3(a) shows loss tangent as a function of frequency 


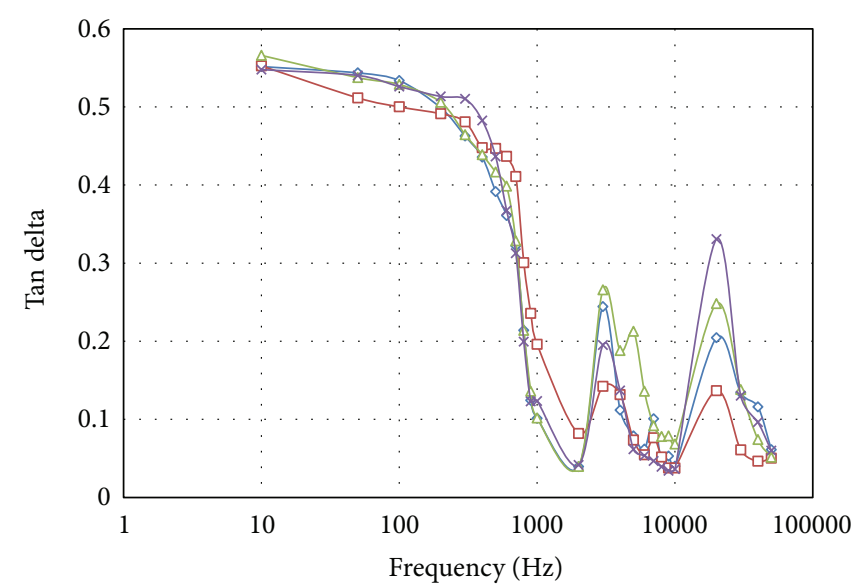

$\diamond$ Pure PVC $\quad \triangle$ PVC $+5 \%$ fumed silica

$\neg-$ PVC $+10 \%$ fumed silica $\rightarrow$ PVC $+1 \%$ fumed silica

(a)

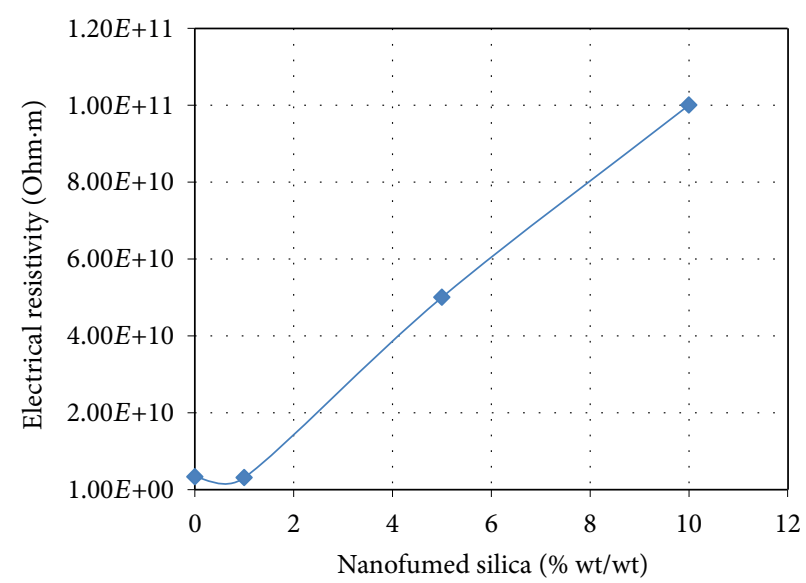

(b)

FIgURE 3: Measured loss tangent (a) and resistivity of PVC nano fumed silica.

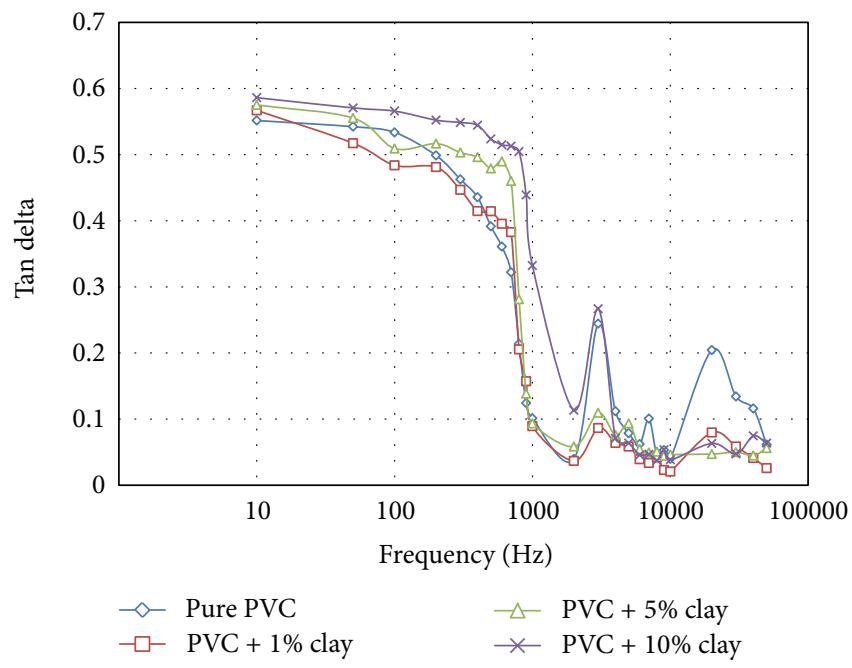

(a)

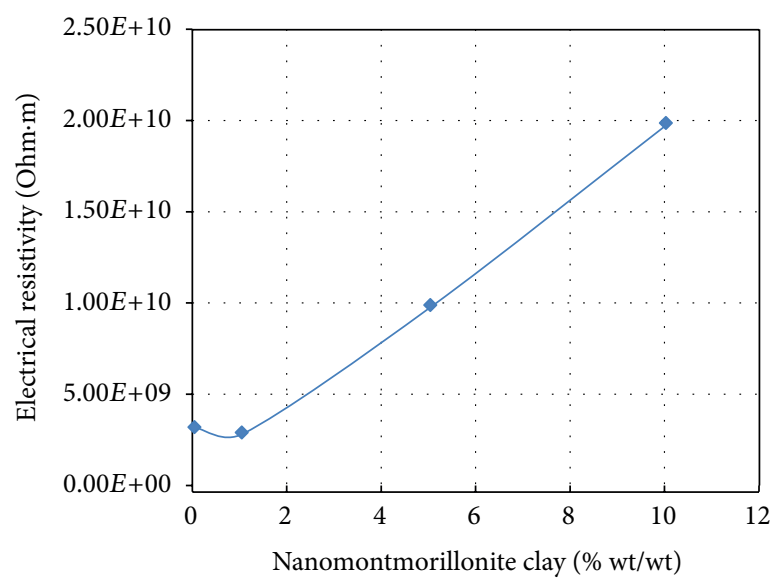

(b)

FIGURE 4: Measured loss tangent (a) and resistivity of PVC-nano montmorillonite clay.

PVC-nano fumed silica at room temperature $\left(25^{\circ} \mathrm{C}\right)$. It is depicted that the loss tangent of PVC nanocomposites increased with increasing the fumed silica loading. The addition of nano-fumed silica from 5 to $10 \% \mathrm{wt} / \mathrm{wt}$ effectively improved the loss tangent values. However, it can be observed that the loss tangent does not enhance below $5 \mathrm{wt} \%$. This can be attributed to the presence of voids at PVC-nano fumed silica interphase due to low melt flow around the nanofumed silica [36]. Electrical resistivity of PVC-nano fumed silica showed higher values than the CES program results (see Figure 3(b)). This can be attributed to the influence of using nanoscale fillers (larger specific area).

3.4. Effect of Nanomontmorillonite Clay on PVC Electrical Properties. Figure 4(a) shows loss tangent as a function of frequency for PVC-nanomontmorillonite clay composites at room temperature $\left(25^{\circ} \mathrm{C}\right)$. It is clear that the loss tangent of PVC nanocomposites decreases with the increasing frequency, while it increases with increasing clay percentage of nanofillers up to $10 \%$ wt. This can be attributed to low response of the PVC dipole to follow the system variations at high frequency [37]. Figure 4(b) shows resistivity as a function of nano-montmorillonite clay loading at room temperature $25^{\circ} \mathrm{C}$. The electrical resistivity of PVCnanomontmorillonite clay composites increases with increasing nanoclay. It is noticed that the resistivity was decreased below $1 \%$ nanomontmorillonite clay which has the same behavior as PVC-nano fumed silica composite.

3.5. SEM Analysis. Microstructure studies were carried out in order to detect voids or agglomerates which can be formed through polymer composite processing. SEM images 




(a)

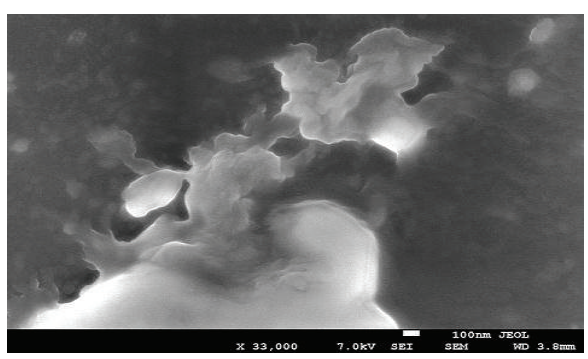

(b)

FIGURE 5: SEM analysis of PVC nanocomposites (10\% wt/wt): (a) nanoclay composites, (b) nanofumed silica.

for PVC composites with nano-montmorillonite and nanofumed silica fillers have been obtained as shown in Figures 5(a) and 5(b). It is depicted that nano fillers are homogenously dispersed up to $10 \% \mathrm{wt} / \mathrm{wt}$. Nanoclay surface treatment using octadecylamine promotes better dispersion of the nanoclay fillers in PVC matrix.

\section{Conclusions}

As the electrical insulation of PVC composites contribute to its tan delta value, the variation of tan delta value in net PVC nanocomposites in lower frequency range may result in the electrical insulation of the nanocomposites having been affected by the presence of nanosize fillers. As this study was carried out under constant temperature, the influence of the relaxation time of the charge carriers on the electrical insulation of PVC nanocomposites can be ignored. Thus, the number of charge carriers and applied frequency become dominating factors of the electrical insulation of PVC nanocomposites. The presence of nanosize fillers inside PVC will restrict the chain mobility and result in increasing electric insulation as such restriction limited the generation of mobile charge and the movement of charge carriers in polymer dielectrics, especially at a lower frequency range where the insulation will play an important role. Thus, the variation of tan delta value at low frequency range may be due to the influence of inorganic fillers' electrical insulation.

\section{Acknowledgment}

The present work was supported by the Deanship of Scientific Research, King Abdulaziz University, Saudi Arabia, Project ID: $1432 / 829 / 388$.

\section{References}

[1] T. Lan and T. J. Pinnavaia, "Clay-reinforced epoxy nanocomposites," Chemistry of Materials, vol. 6, no. 12, pp. 2216-2219, 1994.

[2] W. Feng, A. Ait-kadi, and B. Riedl, "Polymerization compounding: epoxy-montmorillonite nanocomposites," Polymer Engineering and Science, vol. 42, no. 9, pp. 1827-1835, 2002.

[3] M. Sh. Zoromba, M. Bassyouni, and A. Dahshan, "Preparation and mechanico-optical properties of ultraviolet-curable transparent polyurethane elastomer nanocomposites," Journal of
Nanotechnology in Engineering and Medicine, vol. 3, no. 1, Article ID 011008, 5 pages, 2012.

[4] M. Bassyouni, S. A. Sherif, M. A. Sadek, and F. H. Ashour, "Synthesis and characterization of polyurethane-treated waste milled light bulbs composites," Composites B: Engineering, vol. 43, no. 3, pp. 1439-1444, 2012.

[5] M. Bassyouni, I. Taha, S. M.-S. Abdel-Hamid, and L. Steuernagel, "Physico-mechanical properties of chemically treated polypropylene rice straw bio-composites," Journal of Reinforced Plastics and Composites, vol. 31, no. 5, pp. 303-312, 2012.

[6] S. A. Gutub, M. Bassyouni, and S. M. S. Abdel-Hamid, "Dissolved solids adsorption of freshwater using synthesized biofoam composite," Life Science Journal, vol. 10, no. 2, pp. 464-471, 2013.

[7] S. A. Sheriff, M. A. Sadek, F. H. Ashour, and M. Bassyouni, "Effects of surface treatment of ground rice husk on the polyurethane based on castor oil," Polymers and Polymer Composites, vol. 17, no. 8, pp. 481-485, 2009.

[8] A. Z. Simeõs and C. S. Riccardi, "Dielectric spectroscopy analyses of SrBi4Ti4O 15 films obtained from soft chemical solution," Advances in Materials Science and Engineering, vol. 2009, Article ID 928545, 6 pages, 2009.

[9] C. Y. Lai, S. M. Sapuan, M. Ahmad, N. Yahya, and K. Z. H. M. Dahlan, "Mechanical and electrical properties of coconut coir fiber-reinforced polypropylene composites," Polymer - Plastics Technology and Engineering, vol. 44, no. 4, pp. 619-632, 2005.

[10] T. Imai, F. Sawa, T. Yoshimitsu, T. Ozaki, and T. Shimizu, "Preparation and insulation properties of epoxy-layered silicate nanocomposite," in Proceedings of IEEE Conference on Electrical Insulation and Dielectric Phenomena (CEIDP '04), pp. 402-405, October 2004.

[11] D. A. Bolon, "Epoxy chemistry for electrical insulation," IEEE Electrical Insulation Magazine, vol. 11, no. 4, pp. 10-18, 1995.

[12] R. S. Gorur, E. A. Cherney, and J. T. Burnham, Outdoor Insulators, Ravi S Gorur, Phoenix, Ariz, USA, 1999.

[13] R. Hackam, "Outdoor HV composite polymeric insulators," IEEE Transactions on Dielectrics and Electrical Insulation, vol. 6, no. 5, pp. 557-585, 1999.

[14] L. H. Meyer, E. A. Cherney, and S. H. Jayaram, "The role of inorganic fillers in silicone rubber for outdoor insulation-alumina tri-hydrate or silica," IEEE Electrical Insulation Magazine, vol. 20, no. 4, pp. 13-21, 2004.

[15] T. J. Lewis, "Nanometric dielectrics," Philosophical Transactions of the Royal Society, London, vol. A247, pp. 529-551, 1994.

[16] C. Green and A. Vaughan, "Nanodielectrics-how much do we really understand?" IEEE Electrical Insulation Magazine, vol. 24, no. 4, pp. 6-16, 2008. 
[17] B. Venkatasulu and M. J. Thomas, "Erosion resistance of silicone rubber nanocomposites at lower filler loadings," in Proceedings of International Symposium on High Voltage Engineering (ISH '09), pp. 1-6, 2009.

[18] B. Venkatesulu and M. J. Thomas, "Studies on the tracking and erosion resistance of RTV silicone rubber nanocomposite," in Proceedings of Annual Report Conference on Electrical Insulation and Dielectric Phenomena (CEIDP '08), pp. 204-207, October 2008.

[19] I. Ramirez, E. A. Cherney, S. Jayaram, and M. Gauthier, "Silicone rubber nanocomposites for outdoor insulation applications," in Proceedings of Annual Report Conference on Electrical Insulation and Dielectric Phenomena (CEIDP '07), pp. 384-387, October 2007.

[20] G. Iyer, R. S. Gorur, R. Richert, A. Krivda, and L. E. Schmidt, "Dielectric properties of epoxy based nanocomposites for high voltage insulation," IEEE Transactions on Dielectrics and Electrical Insulation, vol. 18, no. 3, pp. 659-666, 2011.

[21] M. S. Naidu and V. Karamaju, High Voltage Engineering, Tata McGraw-Hill, Noida, India, 3rd edition, 2004.

[22] R. I. Buhl, J. Brandrup, M. Bitterner, W. Michaeli, and G. Menges, Recyling and Recovery of Plastics, Carl Hanser, Munich, Germany, 1996.

[23] M. E. Bassiouni, F. Al-Shamy, N. K. Madi, and M. E. Kassem, "Temperature and electric field effects on the dielectric dispersion of modified polyvinyl chloride," Materials Letters, vol. 57, no. 9-10, pp. 1595-1603, 2003.

[24] X.-L. Xie, R. K.-Y. Li, Q.-X. Liu, and Y.-W. Mai, "Structureproperty relationships of in-situ PMMA modified nano-sized antimony trioxide filled poly(vinyl chloride) nanocomposites," Polymer, vol. 45, no. 8, pp. 2793-2802, 2004.

[25] M. M. Ueki and M. Zanin, "Influence of additives on the dielectric strength of high-density polyethylene," IEEE Transactions on Dielectrics and Electrical Insulation, vol. 6, pp. 876-881, 1999.

[26] G. Wypych, Handbook of Fillers, Transcontinental Printing, Quebec, Canada, 2nd edition, 1999.

[27] N. Fuse, Y. Ohki, and T. Tanaka, "Comparison of nano-structuration effects in polypropylene among four typical dielectric properties," IEEE Transactions on Dielectrics and Electrical Insulation, vol. 17, no. 3, pp. 671-677, 2010.

[28] M. Takala, H. Ranta, P. Nevalainen et al., "Dielectric properties and partial discharge endurance of polypropylene-silica nanocomposite," IEEE Transactions on Dielectrics and Electrical Insulation, vol. 17, no. 4, pp. 1259-1267, 2010.

[29] M. Ambid, D. Mary, G. Teyssedre et al., "Effect of filler concentration on dielectric behaviour and on charge trapping in $\mathrm{PP} /$ clay nanocomposites," in Proceedings of Annual Report Conference on Electrical Insulation and Dielectric Phenomena (CEIDP '04), pp. 389-392, October 2004.

[30] L. Bois, F. Chassagneux, S. Parola et al., "Growth of ordered silver nanoparticles in silica film mesostructured with a triblock copolymer PEO-PPO-PEO," Journal of Solid State Chemistry, vol. 182, no. 7, pp. 1700-1707, 2009.

[31] A. Usuki, Y. Kojima, M. Kawasumi et al., "Synthesis of nylon 6-clay hybrid," Journal of Materials Research, vol. 8, no. 5, pp. 1179-1184, 1993.

[32] M. Ochi, R. Takahashi, and A. Terauchi, "Phase structure and mechanical and adhesion properties of epoxy/silica hybrids," Polymer, vol. 42, no. 12, pp. 5151-5158, 2001.

[33] P. O. Henk, T. W. Kortsen, and T. Kvarts, "Increasing the electrical discharge endurance of acid anhydride cured DGEBA epoxy resin by dispersion of nanoparticle silica," High Performance Polymers, vol. 11, no. 3, pp. 281-296, 1999.

[34] A. Thabet and Y. A. Mobarak, "A model for dielectric characterization of nanocomposite polymeric industrial materials," Journal of Engineering Sciences, vol. 40, no. 5, 2012.

[35] A. Thabet and Y. A. Mobarak, "Experimental study for dielectric strength of new nanocomposite polyethylene industrial materials," International Journal of Electrical Engineering and Technology, vol. 3, no. 1, pp. 553-564, 2012.

[36] A. Thabet and Y. A. Mobarak, "Dielectric characteristics of new nano-composite industrial materials," in Proceedings of International Conference on High Voltage Engineering and Application (ICHVE '10), pp. 568-571, New Orleans, La, USA, October 2010.

[37] V. Raja, A. K. Sharma, and V. V. R. N. Rao, "Impedance spectroscopic and dielectric analysis of PMMA-CO-P4VPNO polymer films," Materials Letters, vol. 58, no. 26, pp. 3242-3247, 2004. 

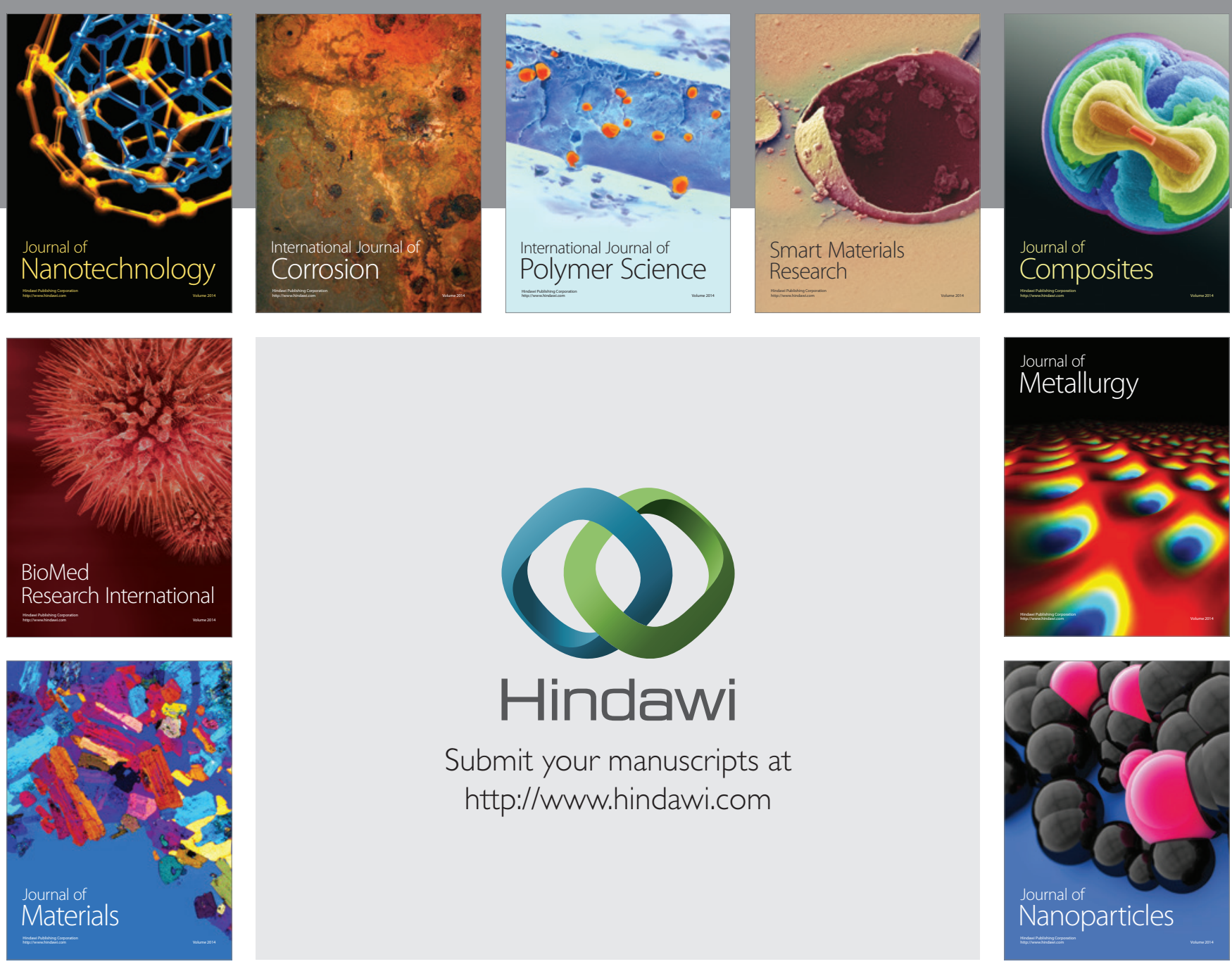

Submit your manuscripts at http://www.hindawi.com
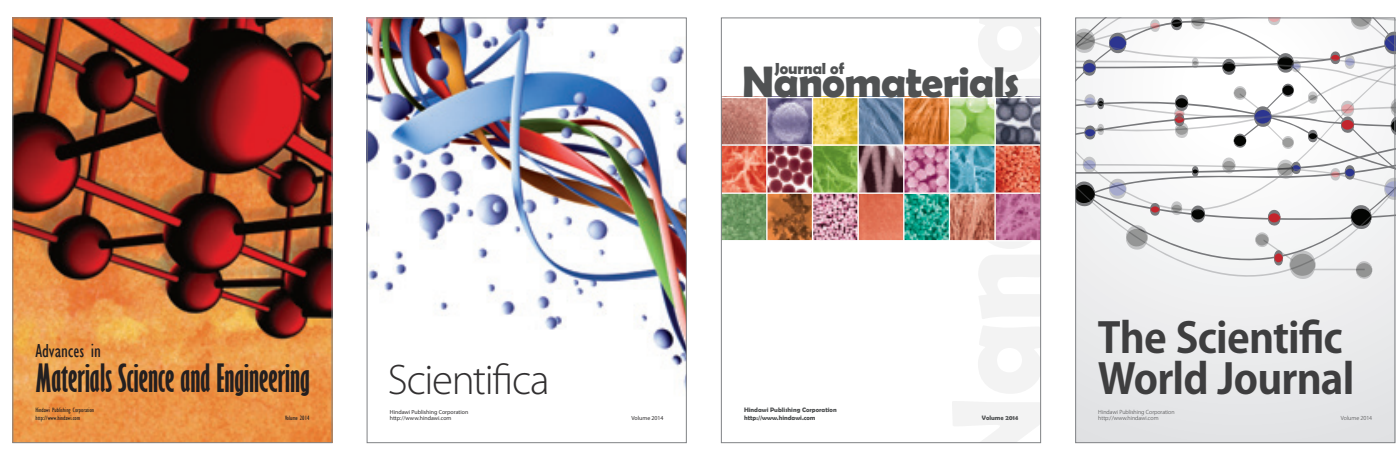

\section{The Scientific World Journal}
